\title{
A metáfora nos sermões de Antonio Vieira: do Argumentativo ao Sacro-Literário
}

\author{
The Metaphor in Antonio Vieira's Sermons: From \\ the Argumentative to the Sacred Literary
}

Murilo Cavalcante Alves ${ }^{*}$

\begin{abstract}
RESUMO
Segundo a Retórica Clássica, as figuras de estilo, tais como a antítese, a hipérbole e a metáfora, dentre outras, na medida em que contribuem para o movere - ao suscitar uma emoção -, o docere - ao transmitir um conhecimento -, e o delectare - ao proporcionar prazer -, são também retóricas, por exprimirem argumentos, condensando-os e tornando-os mais expressivos. Desse modo, o presente artigo incursiona pela utilização da metáfora nos sermões de Antonio Vieira, como criadora de sentido, com o objetivo de identificar sua natureza e função. Desse modo, visualiza a metáfora não apenas como elemento estético, mas também discursivo, se bem que a análise dessa figura se subordine a uma análise prévia dos argumentos. Pressupõe, portanto, a utilização de tal recurso como, inicialmente, argumentativo, de acordo com o que preceitua a Retórica Antiga, mas estende sua percepção para sua possível autonomização, por conta das derivações em que incorre ao integrar campos semânticos diferenciados. Para isso, a pesquisa recorreu aos estudiosos dessa questão, como Araújo (2013), Cantel (1959), Curtius (1979), Gontijo, Massimi (2014), Muraro (2003), Oliveira (2008), Saraiva (1980), dentre outros.
\end{abstract}

Palavras-chave: Sermões de Antonio Vieira; Argumentação; Metáfora.

\footnotetext{
* FALE - Faculdade de Letras da Universidade Federal de Alagoas - UFAL.
} 
According to Classical Rhetoric, style figures, such as the antithesis, hyperbole and metaphor, among others, can contribute to the movere - to elicit an emotion -, docere - to transmit knowledge -, and delectare - to provide pleasure -, they are also rhetorical, to express arguments, condensing them and making them more expressive. Thus, this paper contemplates the use of figures of speech in the sermons of Antonio Vieira, especially metaphor, as a creator of meaning, in order to identify its nature and function. Thus, viewing the metaphor not only as an aesthetic element but also as a discursive one, although the analysis of this figure is subordinated to a previous analysis of the arguments. Therefore it assumes the use of such resource as initially argumentative, according to the precepts of the Old Rhetoric, but extends his perception to its possible autonomy, due to the way it has incurred to integrate different semantic fields. For this, the research appealed to scholars of this issue, as Araújo (2013), Cantel (1959), Curtius (1979), Gontijo, Massimi (2014), Muraro (2003), Oliveira (2008), Saraiva (1980), among others.

Keywords: Antonio Vieira's sermons. Argumentation. Metaphor. 
Alves, M. C.

A metáfora

nos sermões de

Antonio Vieira:

do Argumentativo

ao Sacro-Literário
Revista Letras,

Curitiba, UfPR,

n. 97, pp. 77-89,

jan./jun. 2018.

ISSN 2236-0999

(versão eletrônica)
Nós agora vemos a Deus como por um espelho em enigmas, mas então face a face. Agora conheço-o em parte, mas então hei de conhecê-lo, como eu mesmo sou também dele conhecido.

1 Coríntios 13:12

$\mathrm{S}$ egundo Raymond Cantel (1959), em estudo minucioso sobre o estilo ico, mesmo. Porem, com uma ressalva importante: cada uma das palavras utilizadas pelo jesuíta-orador-escritor apresenta-se dotada de um duplo sentido, ao mesmo tempo em que é concreta, torna-se, por sua vez, figurada. ${ }^{2} \mathrm{O}$ que significa dizer que elas, as palavras, são usadas, também, num sentido metafórico.

Ainda segundo esse autor, o método de composição vieiriano se destaca por ser comparativo, ao se dirigir a um auditório heterogêneo, como certamente deveria ser aquele de suas prédicas; ele fala a linguagem de cada um, fazendo associações alegóricas que se incorporam ao seu discurso religioso. Tal recurso proporciona ao seu discurso a capacidade de ser compreendido em níveis diversos e por auditórios diferenciados. Ou seja, percebe-se que suas palavras parecem assumir uma vida dupla no instante mesmo em que são concretas, pois se tornam também alegóricas, como se a visão metafórica duplicasse a concepção intelectual. O tom, bastante variado, ora pode ser familiar, ora nobre, mas sempre digno e nunca vulgar, como assinala Cantel (1959). ${ }^{3}$

1 CANTEL, Raymond. Les sermons de Vieira: étude du style. 6. ed. Paris: Ediciones Hispano-Americanas, 1959.

2 Cf. o original: "Il aime les termes concrets et précis, les termes techniques même. Mais il faut se rappeler que chacun de ces mots est en général affecté d'un double sens, il est pris à la fois au concret et au figuré. » (CANTEL, 1959, p. 174).

3 Cf. o original: "Sa méthode, en effet, est comparative. Aux artilleurs, il parle de la foudre et 
Tais considerações levam-nos a constatar que tais características se devem, sobretudo, à natureza do vocabulário vieiriano, que demonstra a influência precisa e permanente das Escrituras Sagradas sobre sua forma de escrever. Com efeito, em todos os seus sermões são abundantes as citações bíblicas, citadas da Vulgata, e intercaladas com traduções e comentários. Essa influência bíblica presente em todos os seus escritos, em que, por exemplo, recorre a todas as plantas e animais presentes no Livro Sagrado, parece demonstrar que Vieira não percebeu a natureza senão através das narrações bíblicas. Como judiciosamente observa Muraro (2003):

Nos Sermões, personagens ou exemplos retirados da Bíblia ou da natureza eram colocados em cena e serviam como provas ou argumentos discursivos. Encontram-se ainda nos Sermões outras semelhanças com os Exercícios [de Inácio de Loyola] como o distinguo, as divisões, os arranjos cuidadosos e as múltiplas delimitações. Com certa frequência, tanto Loyola quanto Vieira, recorreram aos recursos das imagens sensoriais na busca de suporte ou materialização das ideias retiradas dos textos sagrados ou da tradição oral. Mais que função ornamental, as imagens sensoriais atuavam como elo entre as diferentes tramas discursivas. A imagem, ao funcionar como alegoria, tornava-se prova na argumentação e assumia a autoridade de texto sagrado ${ }^{4}$.

Não é sem razão que Gontijo e Massimi (2014), por sua vez, percebem e aprofundam essas influências num outro nível de percepção, em que

[...] a intelecção se dá tanto pela apreensão de espécies sensíveis, como espécies inteligíveis (impressas e expressas). Neste dinamismo psíquico, a transformação da coisa para a palavra acontece segundo certa ordem: o objeto suscita, na inteligência do sujeito humano, a espécie sensível impressa, a qual origina a espécie sensível expressa, ou seja, a imagem, ou fantasma da coisa. Tal reprodução representativa do objeto, por sua vez, cria a espécie inteligível impressa, ou seja, proporciona a assimilação intelectual do objeto pela ação do intelecto agente, a saber, o seu reconhecimento pelo intelecto. Finalmente, este reconhecimento produz a espécie inteligível expressa, ou seja, à formulação do conceito, verbum mentis: a palavra. Em suma, o verbum mentis

des canons; aux médecins, aux juges, aux commerçants, aux professeurs, il parle la langue de leur spécialité, qui paraît toujours être la sienne. Son génie lui permet de suivre chacun dans son univers particulier et d'y découvrir des allégories qui peuvent sétendre à tout un discours. Ses mots vivent alors d'une double vie: au moment où il est le plus concret, le plus technique, il est aussi allégorique. La vision métaphorique double la conception intellectuelle. Le ton est trè varié, il peut être noble ou familier, il est toujours digne et jamais vulgaire. Son sens de la retenue et de la pudeur ne peut être pris en défaut ». (CANTEL, 1959, p. 174).

4 MURARO, 2003, p. 33, grifos nossos. 
Alves, M. C.

A metáfora

nos sermões de

Antonio Vieira:

do Argumentativo

ao Sacro-Literário

humano necessita sempre de um veículo sensível: a imagem. Portanto, a retórica enfatiza a função de sinal que a imagem tem, utilizando-se de processos analógicos e imaginativo ${ }^{5}$.

Outro pesquisador a assinalar essa característica vieiriana de intermediar ora personagens bíblicos, ora "profanos", é Rodrigues Filho (s.d.) que, ao analisar o Sermão da Sexagésima, observa que

[...] figuras virtuosas [...] são extraídas da Bíblia e da História profetas, apóstolos, santos -, a fim de persuadir o auditório por meio da emoção - os que por meio de jejuns e preces intentam em seguir os passos de personagens bíblicas ou de homens beatificados. Em ambos os casos, o pregador relaciona as figuras a uma situação real, para estimular, no interlocutor, o desejo de mudança de comportamento seja pela imitação de pessoas com nobreza de caráter, seja pelo abandono da prática de ações iguais às das pessoas corruptas. Figuras como David, Moisés, Cristo, os apóstolos são tomados por Vieira, portanto, como metáforas de nobreza de caráter ${ }^{6}$.

Esse procedimento, certamente apoiado naquele elemento clássico da Retórica, qual seja o ethos, refletia-se de modo semelhante no ethos cristão vieiriano, treinado nos princípios da ideologia inaciana, como comenta Oliveira (2008)

Da mesma maneira que acreditava que o exemplo do pregador deveria ser sempre bom para ser seguido, recuperava esses personagens bíblicos ou históricos, no sentido de oferecer ao público exemplos de coragem, de honestidade, de lealdade, de abnegação, etc. Por intermédio da abordagem dialógica do discurso, é que podemos "conhecer", pela linguagem (criadora de sentidos pela interação entre seus participantes), Vieira como sujeito atuante histórico, social e culturalmente: ele se serviu do cânone sermão pelo que recebeu de sua orientação na Ordem Inaciana, modificando-o (atribuindo-lhe traços de sua subjetividade). O estilo de Vieira, embora submetido a todas as coerções do próprio gênero (argumentação baseada nas Escrituras, escolha do léxico, forma composicional relacionada ao tempo dispendido para a pregação), revela-se ao colocar toda essa composição a favor do que acredita seja melhor para o "rebanho de Cristo"; em outras palavras, o Sermão da Sexagésima refrata a realidade ideológica de Vieira ${ }^{7}$.

Revista Letras,

TTIJO, MASSIMI, 2014, p. 215

6 RODRIGUES FILHO, s.d. apud OLIVEIRA, 2008, p. 90, grifos nossos.

Curitiba, UFPR, 7 OLIVEIRA, 2008, p. 90, grifos nossos. 
Gontijo e Massimi (2014), preocupados em aprofundar a questão do "dinamismo psíquico" em Vieira, traçam uma espécie de percurso de como o sermão é elaborado pelo jesuíta, que parte dos diversos entes irracionais da natureza até chegar aos considerados mais "racionais", sendo que estes últimos são a matéria principal de sua parenética admoestadora:

Vieira parte do gênero das criaturas (criaturas racionais, sensitivas, vegetativas e insensíveis) e chega ao temperamento dos homens. Como ele o faz? O discurso começa criando imagens, as quais partem de elementos básicos (elementares) - gênero das criaturas - recapitulando da memóriaconceitoscorrespondentes a percepçõesconcretas (homem, animal, planta, pedra). A seguir, age na potência cogitativa, reelaborando conceitos: aproximando imagens passo a passo - imagens criadas por palavras que trazem carga afetiva. O homem degenerado (em) passa a ser criatura (perde a origem, o ser). Homem degenerado em não "'", mas é "como se fosse", ou seja, o homem degenerado em pedra, não se torna pedra, mas é "como se fosse" (forma intencional) pedra. Aqui se substitui a ideia concreta de pedra (criatura/objeto), pela representação simbólica/afetiva que ela nos traz (intencionalidade) - é a forma intencional presente na fantasia sendo apreendida e ordenadamente na cogitativa. Através da intencionalidade captada, é possível passar do plano concreto do sensível (dureza, solidez, impenetrabilidade), para o universal abstrato (insensibilidade) ${ }^{8}$.

Por isso, os dois autores entendem que a

Insensibilidade é categoria que qualifica uma posição ética, que apesar de remeter a "temperamento", "personalidade" e, portanto, requerer todo um processo de intelecção para definir o conceito, é acessível de forma bem mais direta, por ser intencional, se temos que é como pedra. O ouvinte pode não conseguir inteligir de forma "pura", racionalizando, mas pode entender a intenção que o discurso propõe, e é por isso que o inteligir passa através da sensibilidade. $\mathrm{O}$ Homem-Pedra reelaborado na cogitativa e devolvido à memória, remete então ao tópico de "vontade endurecida".

Citam, então, Gontijo e Massimi, um trecho do Sermão da Sexagésima para exemplificar o que queriam demonstrar, quando Vieira diz: "Oh! Deus nos livre de vontades endurecidas, que ainda são piores que as pedras. A vara de Moisés abrandou as pedras, e não pode abrandar uma vontade endurecida: Percutiens virga vis silicem, et eressae sunt aquale largissimae. Inratum est cor Pharaonis"10.

8 GONTIJO, MASSIMI, 2014, p. 215-216.

9 GONTIJO, MASSIMI, 2014, p. 216.

10 VIEIRA, 1993, p. 80 apud GONTIJO, MASSIMI, 2014. 
Alves, M. C.

A metáfora

nos sermões de

Antonio Vieira:

do Argumentativo

ao Sacro-Literário
Desse modo, os dois autores assinalam que

Vieira coloca como exemplo [...] para recapitular a idéia do Homem-Pedra, a figura bíblica do Faraó e sua vontade endurecida. Retoma o último conteúdo da memória (Homem- Pedra), dá o exemplo bíblico (concreto) e por indução [...] o aplica a todo um gênero (tipo) de ouvinte - mobilizando novamente a potência cogitativa e estabelecendo uma 'nova' memória: persuade ${ }^{11}$.

Por outro lado, retomando Muraro (2003), este assinala que essa forma de proceder se justificava por conta da exegese bíblica que incorporava mesmo elementos ditos profanos, característica já assinalada por vários autores que detectaram influências clássicas em Vieira, sobretudo de Sêneca:

Hoje, a retórica e a exegese ocupam campos distintos do conhecimento. Na época em que Vieira atuou, esses campos formavam, no orador, uma unidade denominada arte retórica, considerada um dom divino. Os procedimentos discursivos do pregador inaciano, utilizados na fundamentação das suas teses, esgrimiam com a mesma competência os exemplos retirados das Escrituras, da história e da natureza. O uso frequente das figuras de linguagem, de simbolismos e de procedimentos distanciados da lógica tomista não escandalizavam os espíritos seiscentistas. Todos os recursos eram permitidos para desvendar a unidade divina que se manifestava na multiplicidade das coisas criadas. Os ornamentos significavam meios eficazes para despertar o afeto dos ouvintes e conduzi-los à ação. Os verdadeiros sermonistas, assim como os profetas, recebiam poderes equivalentes ao do Criador e a capacidade de convencer os ouvintes como o poder singular das suas palavras. Com frequência, [...] se descobre que o orador inaciano ocupou o lugar de Deus, de Moisés, de Davi ou de outros homens considerados santos como se suas palavras emanassem de lábios quase divinos. Observando atentamente a forma como o pregador jesuíta selecionava os textos sagrados que serviam de balizas orientadoras das suas prédicas, se descobre a importância atribuída à palavra escrita como manifestação do verbo divino. Ao sermonista dotado dos dons da profecia cabia revelar as mensagens ocultas no significado dos termos. Vieira, frequentemente, recorria à explicação etimológica das palavras, pois nela encontrava a força impulsionadora da militância ${ }^{12}$.
Revista Letras, Curitiba, UfPR, n. 97, pp. 77-89, jan./jun. 2018. ISSN 2236-0999 (versão eletrônica)
11 GONTIJO, MASSIMI, 2014, p. 216.

12 MURARO, 2003, p. 322-323, grifos do autor. 
Quanto à utilização etimológica das palavras em suas argumentações, citada acima por Muraro (2003), encontramos exemplos significativos no estudo inovador de Antonio J. Saraiva (1980), O Discurso Engenhoso. Seleciono apenas aquele em que o autor destaca o curioso conceito de Vieira de "etimologia da Natureza", quando o jesuíta deriva, por exemplo, de "luz" o nome "Luzitânia":

Nenhuma terra há, contudo, entre todas as do mundo, que mais se oponha à luz que a Luzitânia. Outra etimologia lhe dei eu no sermão passado; mas, como há vocábulos que admitem muitas derivações, e alguns que significam, por antífrase, o contrário do que soam, assim o entendo deste nome, posto que tão luzido. $\mathrm{O}$ mundo, dizem os gramáticos que se chama Mundo, quia minime mundus, e a morte, Parca, quia nemini parcit. E assim como o mundo se chama Mundo porque é imundo, e a morte se chama Parca porque a ninguém perdoa, assim a nossa terra se pode chamar Luzitânia porque a ninguém deixa luzir. Não é Santo Izidoro nem Marco Varro o autor desta funesta etimologia, senão a mesma Natureza, e o mesmo céu, com o curso e ocaso de suas luzes. A terra mais ocidental de todas é a Luzitânia. E porque se chama Ocidente aquela parte do mundo? Porventura porque vivem ali menos ou morrem mais os homens? Não, senão porque ali vão morrer, ali acabam, ali se sepultam e se escondem todas as luzes do firmamento [...] E se isto sucede aos lumes celestes e imortais, que nos lastimamos, senhores, de ler os mesmos exemplos nas nossas histórias? ? $^{13}$

Por sua vez, um exemplo significativo, dentre outros, da recorrência aos elementos naturais do mundo, neste processo argumentativo-metafórico, é o Sermão de Santo Antonio (aos Peixes), em que Vieira, ao não ser ouvido pelos colonos do Maranhão, apodera-se de uma situação semelhante acontecida com Santo Antonio, que tentara pregar aos homens, e diante da recusa destes em ouvi-lo, "pregou aos peixes":

Entre todos os animais do mundo, os peixes são os mais, e os peixes os maiores. Que comparação têm em número as espécies das aves, e as dos animais terrestres com as dos peixes? Que comparação na grandeza o Elefante com a Baleia? Por isso, Moisés, Cronista da criação, calando os nomes de todos os animais, só a ela nomeou pelo seu: Creavit Deus cete grandia. [ Gn 1:21, E Deus criou as grandes baleias, e todo réptil de alma vivente que as águas abundantemente produziram conforme as suas espécies, e toda ave de asas conforme a sua espécie. E viu Deus que era bom.] $]^{14}$

13 Sermão de Santo António apud SARAIVA, 1980, p. 23-24.

14 VIEIRA, 2003, tomo 1, p. 320, grifos nossos. 
Alves, M. C.

A metáfora

nos sermões de

Antonio Vieira:

do Argumentativo

ao Sacro-Literário
Muito louvor mereceis, peixes, por este respeito e devoção que tivestes aos Pregadores da palavra de Deus, e tanto mais quanto não foi só esta a vez em que assim o fizestes. Ia Jonas, Pregador do mesmo Deus, embarcado em um navio, quando se levantou aquela grande tempestade; e como o trataram os homens, como o trataram os peixes? Os homens lançaram-no ao mar a ser comido dos peixes, e o peixe que o comeu, levou-o às praias de Nínive, para que lá pregasse, e salvasse aqueles homens. É possível, que os peixes ajudam à salvação dos homens, e os homens lançam ao mar os ministros da salvação? Vede, peixes, e não vos venha vanglória, quanto melhores sois que os homens, os homens tiveram entranhas para deitar Jonas ao mar, e o peixe recolheu nas entranhas a Jonas, para o levar vivo à terra ${ }^{15}$.

Mas não se trata apenas de argumentar através da natureza: suas prédicas estão recheadas de outras citações bíblicas direcionadas para seu modo de argumentar. E, de outro modo, sua atração pelas descrições grandiosas, na apresentação de cenas aterradoras, nas quais a cólera dos céus e da natureza se manifesta de maneira veemente, parece apontar que dentre todos os livros da Bíblia o que mais influenciou sua forma de pensar foi o Apocalipse de São João, fato este já constatado por Raymond Cantel. ${ }^{16}$

Nas Escrituras, diz Araújo (2013), Vieira encontra motivos e exemplos numerosos para convencer, orientar e transgredir seu auditório na dimensão evangélica, aliando os mais diferentes pretextos para expor seu pensamento ao racionalismo católico contra pecadores de todos os matizes.

O estilo vieirino se orienta pelo gosto do obscuro, do aprofundado, do difícil, porque eivado do Mistério, do arrebatamento ascético. A circularidade prende o ouvinte até o final de cada peça oratória e a verdade do discurso só ao final fica relativamente, aparente ou, antes, sugerida. A pregação é toda manipulada, via metáfora e mito, o pregador enumerando ações e parábolas, citando de memória passagens da Bíblia, ou da História, ou da Filosofia, para exemplificar, para ilustrar seu raciocínio ${ }^{17}$.

Para Vieira, o trabalho com a linguagem visa intensificar nos ouvintes o temor a Deus. O jesuíta busca, por conseguinte, manter o auditório atento, e seus sermões, calcados nas atribulações e conflitos humanos, são propositalmente extensos, gestuais, grandiloquentes.

15 VIEIRA, 2003, tomo 1, p. 321.

16 Cf. o original: "Létude du vocabulaire de Vieira révèle l'influence précise des Écritures sur sa langue. A chaque page de ses sermons, il cite, commente et traduit un passage de la Bible. Linfluence de celle-ci est partout, toutes ses plantes et presque tous ses animaux sont dans le Livre de Dieu, au point qu'il semble navoir vu la nature quà travers lui. Son goût pour les descriptions grandioses, pour les scènes terrificantes, où se manifeste la colère des cieux et celle de la nature nous révèle enfin que, parmi tous les livres de l'Écriture, celui qui a le plus hanté sa pensée est l'Apocalipse de saint Jean ». (CANTEL, 1959, p. 174).

Revista Letras, 17 ARAÚJO, 2014, p. 79 - 80.
Curitiba, UFPR,

n. 97, pp. 77-89,

jan./jun. 2018.

ISSN 2236-0999

(versão eletrônica) 
Advirtamos que nesta mesma Igreja há tribunas mais altas que as que vemos: [...] Acima das tribunas dos reis, estão as tribunas dos anjos, está a tribuna e o tribunal de Deus, que nos ouve e nos há de julgar. Que conta há-de dar a Deus um pregador no Dia do Juízo? [...] O ouvinte dirá: Não mo disseram. Mas o pregador? [...] Ai de mim, que não disse o que convinha! Não seja mais assim, por amor de Deus e de nós ${ }^{18}$.

Destaque-se que essa forma de escrever, ou mesmo de predicar, não é desproposital. Como assinala Cantel (1959), a natureza intemporal das Escrituras Sagradas garante a perenidade do vocabulário do sermão. Aliás, é um erro atribuir um caráter arcaico a este vocabulário, pois na verdade trata-se de uma linguagem que não se submete à fugacidade do tempo. Por isso essa característica serve tão bem a um autor como Vieira. Enquanto vários predicadores de sua época falseiam a linguagem das Escrituras e dos nomes dos $\operatorname{santos}^{19}$ com metáforas que denunciam de imediato a marca da época, Vieira respeita integralmente a linguagem do texto sagrado, do qual ele frequentemente se utiliza. Dotado de um estilo claro e simples, e cultivando de modo profundo a linguagem dos Livros Sagrados, Vieira apenas caminha a favor das sugestões dos textos bíblicos. Seus comentários são apropriados e retomam os termos empregados por estes textos, assim como as próprias imagens utilizadas. ${ }^{20}$

Dentro desse espírito, Antonio Vieira, em seus sermões, recorre, também, muitas vezes a metáforas minerais e vegetais ${ }^{21}$, isto é, às associações naturais para

18 Sermão da Sexagésima apud OLIVEIRA, 2008.

19 Cf. o original: "Il sélève contre les métaphores qui transforment les noms des saints em autant dénigmes : 'Assim o disse o Cetro penitente : assim o disse o Evangelista Apelles: assim o disse a Águia de África, o Favo de Claraval, a púrpura de Belém, a Boca de ouro" (VIEIRA I, 43 apud CANTEL, 1959, p. 39).

20 Cf. o original: "Le caractère éternel de l'Écriture Sainte est une garantie de pérennité pour le vocabulaire du sermon. C'est à tort qu'on lui attribuerait un caractère d'archaïsme. Il s'agit en réalité d’un langage qui échappe à la lois du temps. Or, ce caractère joue pleinement en faveur d'un auteur comme Vieira. Alors que de nombreux prédicateurs de son temps travestinent la langue de l'Écriture et des noms des saints des métaphores qui accusent vite la marque de lâge, Vieira respecte intégralement la langue du texte sacré, dont il fait un usage très fréquent. Partisan d'un style clair et simple, et admirant profondément la langue des Écritures, il obéit aux suggestions du texte biblique. Son commentaire en reprend les termes et en reprend les images ». (CANTEL, 1959, p. 57).

21 Sobre esse tipo de metáforas, vejam o que diz Ernst Curtius: "[...] a principal fonte do metaforismo alimentar é a Bíblia. O comer o fruto proibido e a instituição da ceia do Senhor formam dois capítulos dramáticos da história sagrada cristã. São considerados bem-aventurados os que sofrem fome e sede. No Evangelho de João $(4,13$ e seg.; 6, 27) distinguem-se a água terrena e a da vida eterna, a comida que perece e a qui permanet in vitam aeternam. Os cristãos recém-convertidos são comparados a criancinhas (I Cor. 3,2; I Pedro 2, 2; Hebr. 5, 12 e seg.), que necessitam de leite, e não de alimento sólido. (21. Quanto ao leite nas escrituras cristãs, cp. Fr. Dornseiff, Das Alphabet in Mystik und Magic, 2, 18 e seg. - Diz-se num texto de filosofia indiana: "A manteiga fresca, recém-batida, do leite da perfeição." (Kaivalya-navanîta) Heinrich Zimmer, Der Weg zum Selbst, Zürich, 1944, 56). A literatura eclesiástica introduziu diversas modificações nessa e noutras imagens, que, aqui, não podemos desenvolver. Aponte-se apenas como fundado o metaforismo alimentar de Agostinho. Aprender e comer não deixam de assemelhar-se; em ambos os casos, convém tornar mais saboroso o alimento com especiarias: inter se habent nonnullam similitudinem vescentes atque discentes; propter fastidia plurimorum etiam ipsa, sine quibus vivi non potest, alimenta condienda sunt. (22. "Entre os que comem e os que estudam há algo de semelhante: por causa do fastio muito generalizador, mesmo os alimentos, sem os quais não se pode viver, devem ser condimentados.” (T. da R.)). (De Doct. Chr. 
Alves, M. C.

A metáfora

nos sermões de

Antonio Vieira:

do Argumentativo

ao Sacro-Literário aproximar o pensamento sagrado da ideia a ser transmitida, como podemos ver, por exemplo, nos trechos abaixo, colhidos no Sermão da Sexagésima e no Sermão de Santo Antônio (aos Peixes), respectivamente:

O trigo que semeou o Pregador Evangélico, diz Cristo, que é a palavra de Deus. Os espinhos, as pedras, o caminho, e a terra boa, em que o trigo caiu, são os diversos corações dos homens. Os espinhos são os corações embaraçados com cuidados, com riquezas, com delícias; e nestes afoga-se a palavra de Deus. As pedras são os corações duros e obstinados; e nestes seca-se a palavra de Deus, e se nasce, não cria raízes. Os caminhos são os corações inquietos e perturbados com a passagem e tropel das coisas do mundo, umas que vão, outras que vêm, outras que atravessam, e todas passam; e nestes é pisada a palavra de Deus, porque ou a desatendem, ou a desprezam. Finalmente, a terra boa são os corações bons, ou os homens de bom coração; e nestes prende e frutifica a palavra divina, com tanta fecundidade e abundancia, que se colhe cento por um: Et fructum fecit centuplum ${ }^{22}$.

Suposto, pois, que, ou o sal não salgue, ou a terra se não deixe salgar; que se há de fazer a este sal, e que se há de fazer a esta terra? O que se há de fazer ao sal, que não salga, Cristo o disse logo: Quod si sal evanuerit, in quo salietur! Ad nihilum valet ultra, nisi ut mittatur foras, et conculcetur ab hominibus. ${ }^{23}$ Se o sal perder a substância e a virtude, e o Pregador faltar à doutrina, e ao exemplo; o que se lhe há de fazer, é lançá-lo fora como inútil, para que seja pisado de todos. Quem se atrevera a dizer tal coisa, se o mesmo Cristo a não pronunciara? Assim como não há quem seja mais digno de reverência, e de ser posto sobre a cabeça, que o Pregador, que ensina e faz o que deve; assim é merecedor de todo o desprezo, e de ser metido debaixo dos pés, o que com a palavra, ou com a vida prega o contrário ${ }^{24}$.
Revista Letras, Curitiba, UFPR, n. 97, pp. 77-89, jan./jun. 2018. ISSN 2236-0999 (versão eletrônica)
IV, 11, 23).Para Agostinho Deus é interior cibus (Conf. I, 13, 21, 5), a verdade é alimento (Civ. Dei XX, 30, 21) e comida (Conf. IX, 10,24, 12). No emprego do conceito 'condimentar' ('salgar'), Agostinho também está com a tradição bíblica (por exemplo, Col. 4, 6: sermo vester in sale sit conditus) ("O vosso discurso seja sempre temperado com sal") (T. da R.), que depois encontramos em Walaffrid. Este denomina a sua Gallusvita, em prosa, de agreste pulmentum ("Iguaria agreste"), que condimentará com sal, isto é, metrificará (Poetae, II, 428, VI, 4, nota 5). De origem bíblica é também a designação de comida dada à doutrina cristã (coena mea: Luc. 14,24; coena magna Dei: Apoc. 19, 17 e outros). Daí se derivam locuções como lucifer pastus ("Pasto luminoso"), em Prudêncio (Psychom. 625), cena spiritalis, em Válter de Châtillon (Moralisch-satirische Gedichte, ed. Strecker, pág. 101, estr. 7). Gregório o Grande chama aos escritos de Agostinho farinha de trigo; ao seu próprio farelo (MGH Epist. II, 251, 30 e segs.) Um poeta do século IX compara a doutrina de Cristo com um alimento vital, condimentado com mel, azeite e vinho tinto de Falerno (Poetae, III, 258, 49 e segs.)" (CURTIUS, 1979, p. 140-141). Como se vê por esses comentários, Vieira, ao utilizar tais metáforas, estava integrado ao espírito mais tradicional e vivo do cristianismo agostiniano.

22 VIEIRA, Sermão da Sexagésima, 2003, tomo 1, p. 32, grifos nossos.

23 Mt 5:13 [se o sal for insípido, com que há de se salgar? Para nada mais presta, senão para se lançar fora e ser pisado pelos homens].

24 VIEIRA, 2003, “Sermão de Santo António (aos Peixes)", tomo 1, p. 317-318, grifos nossos. 
Isto é o que se deve fazer ao sal, que não salga. E à terra, que se não deixa salgar, que se lhe há de fazer? Este ponto não resolveu Cristo Senhor nosso no Evangelho; mas temos sobre ele a resolução de nosso grande Português Santo Antônio, que hoje celebramos, e a mais galharda e gloriosa resolução que nenhum Santo tomou ${ }^{25}$.

Aliás, essa recorrência vieiriana às inúmeras metáforas saídas da natureza, encontra apoio no próprio Evangelho, rico em metáforas naturais que o orador luso-brasileiro utiliza para fazer associações e comparações de natureza moral, o que se coadunava com o espírito de sua parenética centrada no ethos e nos exempla, numa espécie de circunvolução em torno de um único ponto, que ora remetia ao Velho Testamento, ora ao Novo Testamento. Isso tudo em consonância com seu espírito conceptista.

25 VIEIRA, Sermão de Santo António (aos Peixes), 2003, tomo I, p. 318. 
Alves, M. C.

A metáfora

nos sermões de

Antonio Vieira:

do Argumentativo

ao Sacro-Literário
ARAÚJO, Jorge de Souza. António Vieira e a parenética religiosa. Revista SEMEAR 2. Disponível em: <http://www.letras.puc-rio.br/unidades\&nucleos/catedra/ revista/2Sem_03.html>. Acesso em: 20 mar. de 2014.

CANTEL, Raymond. Les sermons de Vieira: étude du style. Paris : Ediciones Hispano-Americanas, 1959.

CURTIUS, Ernest Robert. Literatura europeia e Idade Média latina. 2. ed. Brasília: Instituto Nacional do Livro, 1979.

GONTIJO, Sandro Rodrigues; MASSIMI, Marina. A persuasão e o dinamismo psíquico em sermões de Antônio Vieira. Disponível em: <www.scielo.br/paideia>. Acesso em: 12 abr. de 2014.

MURARO, Valmir Francisco. Padre Antônio Vieira: retórica e utopia. Florianópolis: Insular, 2003.

OLIVEIRA, Lucimara de. O Sermão da Sexagésima: uma Arena de Vozes. 2008. 144f. Dissertação (Mestrado em Linguística Aplicada e Estudos da Linguagem). Pontifícia Universidade Católica de São Paulo, São Paulo, 2008.

SARAIVA, Antonio J. O discurso engenhoso: estudos sobre Vieira e outros autores barrocos. São Paulo: Perspectiva, 1980.

VIEIRA, Antonio. Sermões. Org. e int. de Alcir Pécora. 3. reimp. São Paulo: Hedra, 2003. Tomo I.

Submetido em: 04/12/2017

Aceito em: 14/05/2018

Revista Letras, Curitiba, UFPR, n. 97, pp. 77-89, jan./jun. 2018. ISSN 2236-0999 (versão eletrônica) 